\title{
Amine functionalized radiation induced grafted polyolefin nanofibers for $\mathrm{CO}_{2}$ adsorption
}

\begin{abstract}
A new type of nanofibrous amine-containing adsorbent was prepared for $\mathrm{CO}_{2}$ adsorption by electrospinning of syndiotactic polypropylene (s-PP) followed by radiation induced grafting of glycidyl methacrylate and subsequent amination with ethanolamine. The obtained adsorbents were tested for $\mathrm{CO}_{2}$ adsorption with a mixture of $\mathrm{CO}_{2} / \mathrm{N}_{2}$ having $5-15 \% \mathrm{CO}_{2}$ using a fixed bed adsorption column at atmospheric pressure. A maximum adsorption capacity of $2.87 \mathrm{mmol} / \mathrm{g}$ was achieved for the sample with degree of grafting of 300\% and degree of amination of $94 \%$ at feed concentration of $15 \%$ at $30^{\circ} \mathrm{C}$. This was accompanied by good mechanical characteristics and a very high amine efficiency that reached $75 \%$ at room temperature, suggesting that the obtained fibrous adsorbent has high potential for $\mathrm{CO}_{2}$ adsorption.
\end{abstract}

Keyword: $\mathrm{CO}_{2}$ adsorption; Solid supported adsorbent; Radiation induced grafting; Nanofibers; Glycidyl methacrylate 